\title{
Changes in intracellular redox status influence multidrug resistance in gastric adenocarcinoma cells
}

\author{
DE-JUN TAI ${ }^{1}$, WEN-SEN JIN ${ }^{2}$, CHENG-SI WU ${ }^{1}$, HONG-WEI SI ${ }^{3}$, \\ XIAN-DONG CAO ${ }^{1}$, AI-JUN GUO ${ }^{1}$ and JIA-CONG CHANG ${ }^{1}$ \\ ${ }^{1}$ Department of General Surgery, The First Affiliated Hospital, ${ }^{2}$ Teaching and Research Section of Nuclear Medicine, and \\ ${ }^{3}$ Department of Nuclear Medicine, The First Affiliated Hospital, Anhui Medical University, Hefei 230032, P.R. China
}

Received March 18, 2012; Accepted May 15, 2012

DOI: $10.3892 /$ etm.2012.591

\begin{abstract}
Multidrug resistance (MDR) to chemotherapeutic agents is a major obstacle for the treatment of various types of cancers. The exact mechanism of MDR has not yet been fully clarified, although it has been frequently associated with the variation of intracellular redox status. The levels of intracellular glutathione (GSH) are considered to play a vital role in the regulation of the intracellular redox status. In our study, we investigated the effects of buthionine sulfoximine (BSO), an inhibitor of GSH biosynthesis, and NAC, a cysteine source for GSH synthesis, on sensitive gastric adenocarcinoma cells (SGC7901) and cisplatin-resistant SGC7901/DDP cells using the 3-(4,5-dimethylthiazol-2-yl)-2,5-diphenyltetrazolium bromide (MTT) assay. The two cell lines were pretreated with various non-toxic concentrations of BSO for $24 \mathrm{~h}$ and combined with fluorouracil (5-FU) or mitomycin (MMC) in the presence or absence of NAC before culturing further. After various treatments, the $\mathrm{IC}_{50}$ values of $\mathrm{MMC}$ and 5-FU were calculated and intracellular GSH levels were measured using the glutathione reductase/5,5'-dithiobis-(2-nitrobenzoic acid) (DTNB) recycling assay without anticancer drug stimulation under the same microenvironments. The study demonstrated that BSO increased the sensitivity of the cells to chemotherapeutics while NAC exhibited the reverse effect, particularly in drug-resistant cells. It is, therefore, possible that changes in intracellular GSH levels affect the chemosensitivity of the resistant cells to a greater extent than that of their parent cells. This study indicates that variation in the intracellular redox status may be closely correlated with MDR and may provide a valuable basic strategy for anticancer therapy.
\end{abstract}

Correspondence to: Dr Jia-Cong Chang, Area II, Department of General Surgery, The First Affiliated Hospital of Anhui Medical University, Meishan Road, Hefei 230032, P.R. China

E-mail: changjiacong@126.com

Key words: multidrug resistance, glutathione, redox status, gastric adenocarcinoma cells

\section{Introduction}

Gastric cancer is the second most common cause of cancer-related mortality and morbidity worldwide, accounting for almost $12 \%$ of cancer-related mortality and $1.6 \%$ of total mortality (1-3). Postoperative chemotherapy is used as a supplementary treatment to prevent tumor recurrence and metastasis $(4,5)$. Several retrospective studies have reported that supplementary chemotherapy may improve the quality of life and total survival (6-9). However, the emergence of drug resistance, particularly multidrug resistance (MDR), has prevented successful treatment in a large proportion of patients (10). The two main forms of MDR are intrinsic resistance, in which the previously untreated cancer cells are inherently insensitive to chemotherapeutic drugs, and acquired resistance, in which the cancer cells become insensitive as a result of chemotherapy $(11,12)$. The most commonly reported mechanism for the acquisition of resistance to a broad range of anticancer drugs is the expression of one or more energy-dependent transporters, including P-glycoprotein (P-gp), multidrug resistance-associated proteins (MRPs), lung resistance protein (LRP) and breast cancer resistance protein (BCRP/MXR/ABCG2) (12-19). These transporters mediate drug efflux from tumor cells and may further cause cross-resistance to multiple drugs with diverse chemical structures and curative efficacies. According to previous studies, MDR is observed in the majority of gastric cancers during treatment and is an significant cause of treatment failure $(19,20,21)$.

Glutathione (GSH) is the tripeptide thiol L- $\gamma$-glutamylL-cysteinyl-glycine, a ubiquitous endogenous antioxidant. Its main functions are the protection of the intracellular environment from oxidative stress and the detoxification of cells by inactivation of xenobiotics (22). As the predominant cellular thiol, intracellular GSH concentrations may exceed $10 \mathrm{mM}$ (23). Levels of GSH are reported to be elevated in various tumor cells, for example in bone marrow, breast, ovary, colon, larynx and lung cancer cells (24-29). Elevated levels of GSH are often associated with an increased resistance to cancer chemotherapeutic agents due to the protective conjugation and detoxification effects of GSH (30). Similarly, other studies have shown that cross-resistance to a number of drugs, including cyclophosphamide, melphalan, mechlorethamine, 
platinum-containing compounds and sulfhydryl-reactive chemotherapeutic drugs, correlates with increased levels of intracellular GSH (31-33). Conversely, the depletion of intracellular GSH has been revealed to decrease the resistance of cancer cells to multiple chemotherapeutic agents (30). However, to date there have been few studies comparing the levels of GSH in multidrug resistant cancer cell lines with those in the parent cancer cell lines and it remains unclear whether the alteration of intracellular GSH levels generates different effects on the cross-resistance of multidrug resistant and parent cell lines.

In the present study, we monitored the levels of intracellular $\mathrm{GSH}$ in a gastric adenocarcinoma cell line with resistance to cisplatin (CDDP) and in its parent cell line. A GSH synthesis inhibitor and/or stimulator were used to change intracellular GSH levels in order to evaluate the effects of GSH on the chemosensitivities of the two cell lines.

\section{Materials and methods}

Cell culture and treatment. The human gastric adenocarcinoma cell line SGC7901 and its MDR subline SGC7901/DDP were purchased from Nanjing KeyGen Biotech Co., Ltd. (Nanjing, China). The cells were cultured in RPMI-1640 medium (Gibco-BRL, Carlsbad, CA, USA) supplemented with $10 \%(\mathrm{v} / \mathrm{v})$ fetal bovine serum, penicillin $(100 \mathrm{U} / \mathrm{ml})$ and streptomycin $(100 \mu \mathrm{g} / \mathrm{ml})$ at $37^{\circ} \mathrm{C}$ in an incubator containing a humid atmosphere of $95 \%$ air and $5 \% \mathrm{CO}_{2}$. To maintain the MDR phenotype, CDDP (final concentration $800 \mathrm{ng} / \mathrm{ml}$ ) was added to the medium for the SGC7901/DDP cells. The cells were propagated according to the instructions provided by the American Type Culture Collection.

Cell viability assays. The survival ratios of the cells were determined using a 3-(4,5-dimethylthiazol-2-yl)-2,5-diphenyltetrazolium bromide (MTT) colorimetric assay. The cells were seeded in 96-well microplates at a density of $2 \times 10^{3}$ cells per well. Then the cells were treated with the following methods. i) Cells were treated with various concentrations of CDDP, fluorouracil (5-FU) or mitomycin (MMC) for $36 \mathrm{~h}$; ii) The cells were pretreated with various nontoxic concentrations of L-buthionine-(S,R)-sulfoximine (BSO, Sigma, St. Louis, MO, USA) for $24 \mathrm{~h}$, washed 3 times with PBS before replacing fresh medium with various concentrations of 5-FU or MMC combined with or without $5 \mathrm{mM} \mathrm{N}$-acetylcysteine (NAC, Sigma) for $36 \mathrm{~h}$; iii) The cells were treated with various concentrations of 5-FU or MMC combined with $5 \mathrm{mM} \mathrm{NAC}$ for $36 \mathrm{~h}$. Then the medium was replaced with fresh medium, allowing the cells to be continuously grown for up to $72 \mathrm{~h}$. The MTT (Sigma) dye was added to a final concentration of $50 \mathrm{mg} / \mathrm{ml}$ and the cells were subsequently incubated for another $4 \mathrm{~h}$ at $37^{\circ} \mathrm{C}$. The medium containing residual MTT dye was carefully aspirated from each well and $150 \mu 1$ DMSO was added to dissolve the reduced formazan dye. The effect of 5-FU or MMC on the growth of the cells was determined from the differences in absorbance. The fraction of viable cells was calculated by comparing the optical absorbance of the 5-FUor MMC-treated culture with that of the untreated control. The $50 \%$ inhibitory concentration $\left(\mathrm{IC}_{50}\right)$ value was calculated on the basis of the fraction of viable cells.
Intracellular GSH assay. Following the treatment of triplicate samples of $10^{6}$ cells with various reagents, the intracellular levels of GSH were measured using the glutathione reductase/5,5'-dithiobis-(2-nitrobenzoic acid) (DTNB) recycling assay kit (Beyotime Institute of Biotechnology, Haimen, China), following the methods recommended by the manufacturer. Briefly, GSH was determined using a reaction mixture containing $50 \mu \mathrm{l}$ cell lysates, $50 \mu \mathrm{l} 2.4 \mathrm{mM}$ DTNB and $50 \mu \mathrm{l}$ $10.64 \mathrm{mU} / \mu \mathrm{l}$ glutathione reductase in an assay buffer $(\mathrm{pH} 7.5)$ containing $153 \mathrm{mM}$ sodium phosphate and $8.4 \mathrm{mM}$ EDTA. After a 5 -min incubation at $25^{\circ} \mathrm{C}$, the reaction was initiated by the addition of $50 \mu \mathrm{l}$ NADPH solution $(0.16 \mathrm{mg} / \mathrm{ml})$ in assay buffer. The standard and test sample cuvettes were placed into a dual-beam spectrophotometer and the absorbance at $412 \mathrm{~nm}$ was followed as a function of time.

Statistical analysis. Data are reported as the means \pm SEM of three separate experiments. Statistical significance was measured by the independent samples t-test and analysis of variance. A value of $\mathrm{p}<0.05$ was considered to indicate a statistically significant result.

\section{Results}

Selection of the sublethal concentration of BSO. The cytotoxicity of BSO (Sigma), a specific inhibitor of GSH biosynthesis, was evaluated by MTT assay. As shown in Fig. 1, the cell viability gradually reduced concomitantly with the increase in BSO concentration. The $\mathrm{IC}_{50}$ value of BSO in the SGC7901 cells, calculated using the Hill equation, was $3.43 \mathrm{mg} / \mathrm{ml}$. There were non-significant reductions in the viabilities of the cells exposed to the various concentrations of BSO below $20 \%$ $\mathrm{IC}_{50}(\mathrm{p}>0.05)$. Hence, the concentrations of BSO were set at $20 \% \mathrm{IC}_{50}(0.686 \mathrm{mg} / \mathrm{ml}), 10 \% \mathrm{IC}_{50}(0.343 \mathrm{mg} / \mathrm{ml})$ and $5 \% \mathrm{IC}_{50}$ $(0.172 \mathrm{mg} / \mathrm{ml})$ in subsequent studies.

Effects of BSO on the chemosensitivity of cells. The sensitivities of the tumor cells to CDDP, MMC and 5-FU are shown in Fig. 2. The SGC7901/DDP cells exhibited stronger resistance than the parent cells to the three drugs; 6.20-fold for CDDP, 3.49-fold for 5-FU and 1.97-fold for MMC ( $\mathrm{p}<0.01)$. These results indicate that SGC7901/DDP cells are cross-resistant to other chemotherapeutic drugs.

Following the pretreatment of the cells with various concentrations of $\mathrm{BSO}$, the $\mathrm{IC}_{50}$ values of 5-FU were significantly decreased in the two cell lines (Fig. 3B). BSO also increased the chemosensitivity of the SGC7901/DDP cells to MMC. Although BSO slightly reduced the viability of the MMC-treated SGC7901 cells, the difference between the chemosensitivities of the cells with and without BSO pretreatment was not statistically significant (Fig. 3A). These results also revealed that, following BSO treatment, the SGC7901/DDP cells were more sensitive than the SGC7901 cells to 5-FU and MMC.

Effects of $N$-acetylcysteine (NAC) on the chemosensitivity of cells. A GSH precursor, NAC (5 mM), was used to further investigate alterations in the chemosensitivities of the cells. Marked increases in the $\mathrm{IC}_{50}$ values of MMC and 5-FU in the SGC7901/DDP cells were observed (Fig. 4). The resistance of 


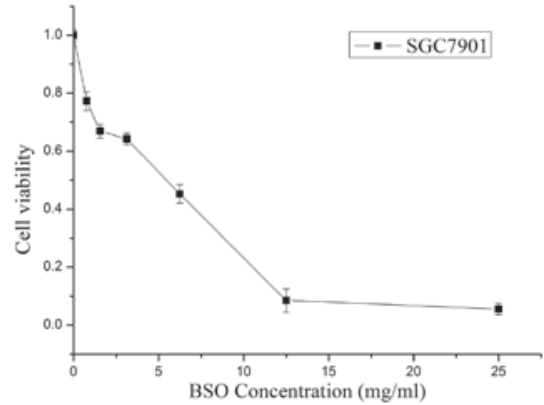

Figure 1. Selection of the sublethal concentration of BSO. SGC7901 cells were exposed to various concentrations of $\operatorname{BSO}(25,12.5,6.25,3.13,1.56$ and $0.78 \mathrm{mg} / \mathrm{ml}$ ). The cell viability was equivalent to the ratio OD treated/OD control. The $\mathrm{IC}_{50}$ value of $\mathrm{BSO}$, calculated using the Hill equation, was $3.43 \mathrm{mg} / \mathrm{ml}$. BSO, buthionine sulfoximine.

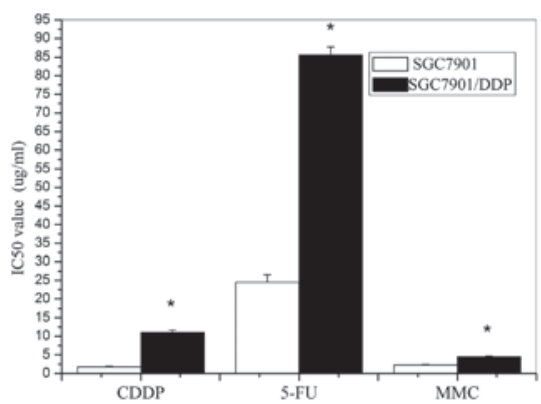

Figure 2. $\mathrm{IC}_{50}$ values of CDDP, 5-FU and MMC for SGC7901 and SGC7901/ DDP cells. The $\mathrm{IC}_{50}$ values of CDDP, 5-FU and MMC for the SGC7901/DPP cells were significantly higher than those of the SGC7901 cells $\left({ }^{*} \mathrm{p}<0.01\right)$. CDDP, cisplatin; 5-FU, fluorouracil; MMC, mitomycin.

A
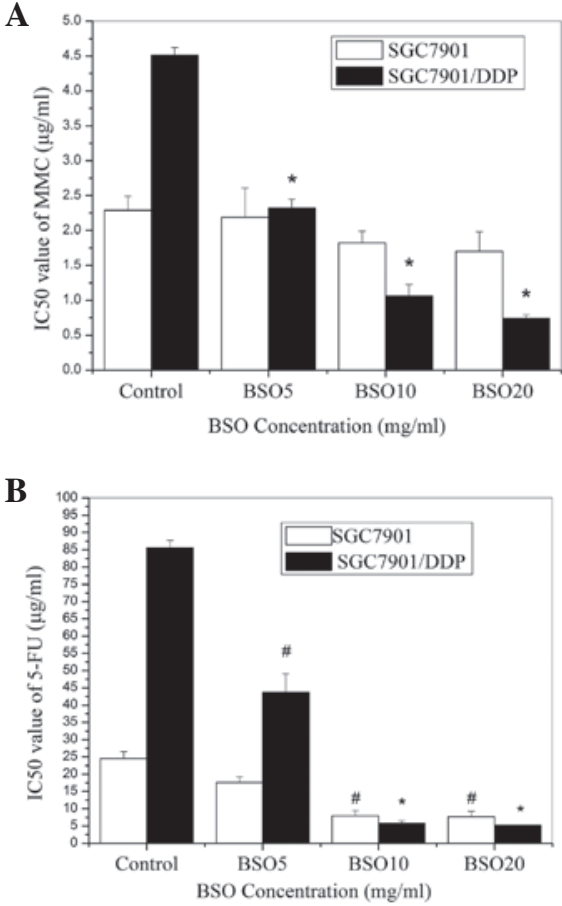

Figure 3. Effects of BSO on the chemosensitivity of SGC7901 and SGC7901/ DPP cells. $\mathrm{IC}_{50}$ values for (A) MMC and (B) 5-FU in the two cell lines pretreated with various concentrations of BSO. ${ }^{*} \mathrm{p}<0.01,{ }^{*} \mathrm{p}<0.05$ compared with control cells. BSO20, BSO10 and BSO5 represent BSO concentrations of $0.686,0.343$ and $0.172 \mathrm{mg} / \mathrm{ml}$, respectively. BSO, buthionine sulfoximine; MMC, mitomycin; 5-FU, fluorouracil.

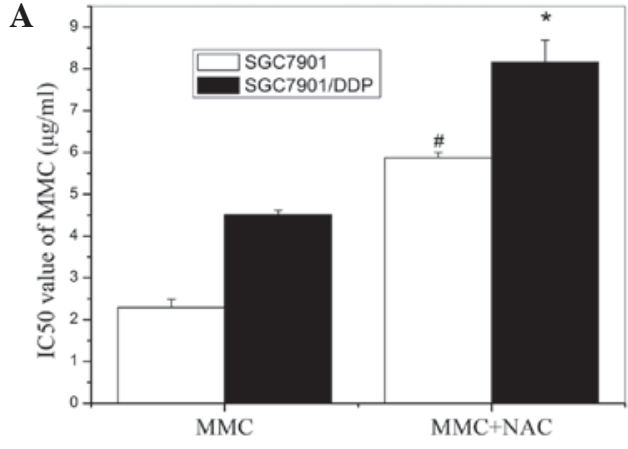

$\mathrm{NAC} 5 \mathrm{mmol} / \mathrm{l}$

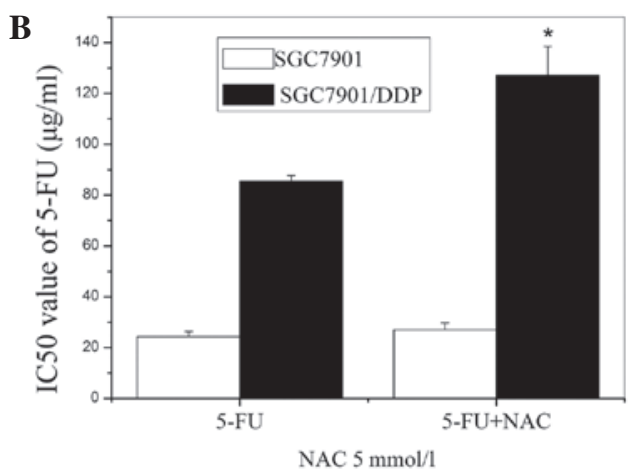

Figure 4. Effects of NAC on the chemosensitivity of SGC7901 and SGC7901/ DDP cells. The cells were cultured with $5 \mathrm{mmol} / \mathrm{l} \mathrm{NAC}$ for $36 \mathrm{~h}$ and exposed to (A) MMC or (B) 5-FU. Cell viability was evaluated by MTT assay. * $\mathrm{p}<0.01$ compared with control SGC7901/DDP cells. ${ }^{*} \mathrm{p}<0.01$ compared with control SGC7901 cells. NAC, N-acetylcysteine; MMC, mitomycin; 5-FU, fluorouracil; MTT, 3-(4,5-dimethylthiazol-2-yl)-2,5-diphenyl-tetrazolium bromide.

the SGC7901 cells to MMC was also elevated by the NAC pretreatment, but the resistance to 5-FU was unchanged.

Effects of combining NAC with BSO on the chemosensitivity of cells. To further examine the responses of the multidrug resistant and parent cells to changes in intracellular GSH levels, NAC was added to the media of the cells pretreated with various concentrations of BSO. The effects of MMC and 5-FU on those cells were then detected and their $\mathrm{IC}_{50}$ values are shown in Fig. 5 . The results reveal that NAC partly reversed the inhibitory effect of $\mathrm{BSO}$ on the chemoresistance of the two cell lines to 5-FU and reduced the inhibitory effect of $\mathrm{BSO}$ on the chemoresistance of SGC7901/DDP cells to MMC. However, no statistically significant effects on the response of the BSO-pretreated SGC7901 cells to MMC were observed, as shown in Fig. 5A. Therefore, the SGC7901/DDP cells appear to be more sensitive than the parent cells to the alteration of cellular GSH.

Alteration of intracellular GSH. The intracellular GSH levels in the two cell lines, after various pretreatments, are shown in Fig. 6. The SGC7901/DDP cells had higher GSH levels than the SGC7901 cells and treatment with NAC alone increased the levels of GSH in the two cell lines. Conversely, in the two cell lines treated with various concentrations of BSO, significant reductions of intracellular GSH levels occurred in a concentration-dependent manner. Subsequent experiments revealed that the inhibition of intracellular GSH by BSO treatment was partially reversed by the addition of NAC. The trends 
A

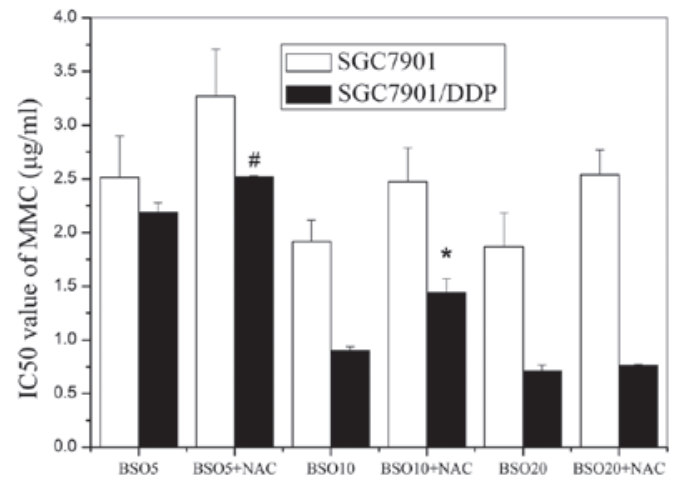

B

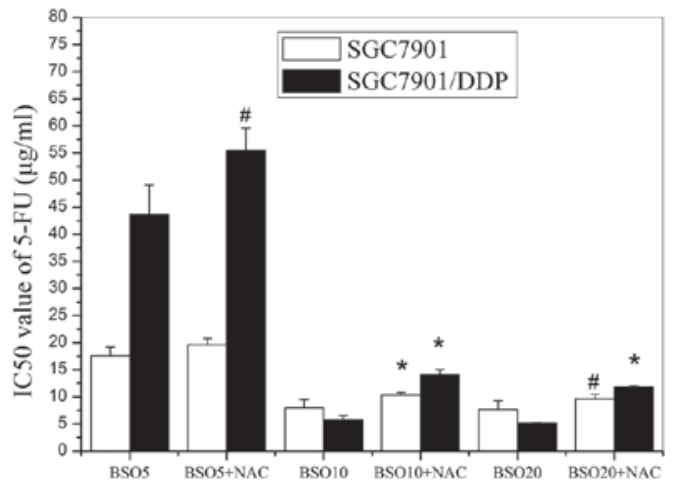

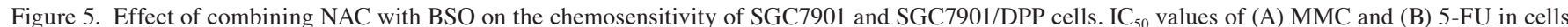
pretreated with various concentrations of $\mathrm{BSO}$ and then treated with NAC. ${ }^{\#} \mathrm{p}<0.05,{ }^{*} \mathrm{p}<0.01$ compared with cells treated with BSO alone. BSO20, BSO10 and BSO5 represent BSO concentrations of $0.686,0.343$ and $0.172 \mathrm{mg} / \mathrm{ml}$, respectively. BSO, buthionine sulfoximine; NAC, N-acetylcysteine; MMC, mitomycin.

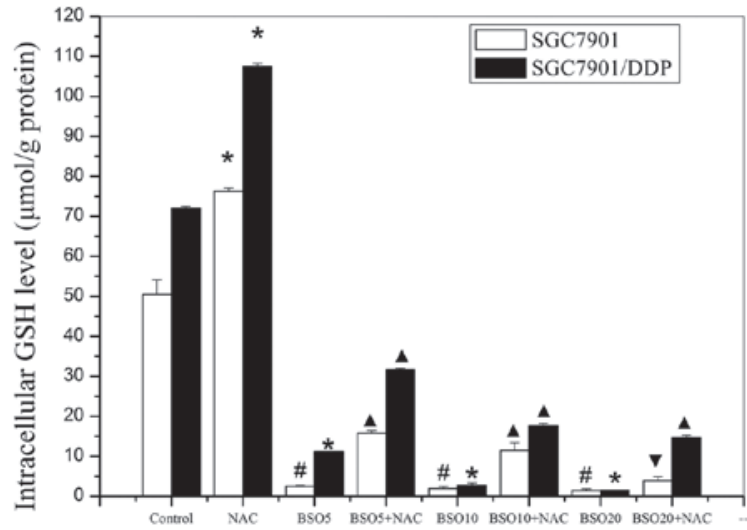

Figure 6. Variations of intracellular redox status following various pretreatments. Intracellular GSH levels following pretreatment with various concentrations of BSO and/or NAC. ${ }^{*} \mathrm{p}<0.01,{ }^{\#} \mathrm{p}<0.05$ compared with control cells; ${ }^{\star} \mathrm{p}<0.01,{ }^{\mathrm{p}}<0.05$ compared with cells treated with the same concentration of BSO. BSO20, BSO10 and BSO5 represent BSO concentrations of $0.686,0.343$ and $0.172 \mathrm{mg} / \mathrm{ml}$, respectively. GSH, glutathione; BSO, buthionine sulfoximine; NAC, N-acetylcysteine.

in the alteration of intracellular GSH levels were consistent with those in chemoresistance of the SGC7901/DDP cells but not those in the SGC7901 cells.

\section{Discussion}

The resistance of cancer cells to a single drug is usually accompanied by resistance to other chemotherapeutic drugs (34-36). It is well known that CDDP acts on multiple cellular targets representing various signal transduction pathways. It is therefore conceivable that multiple mechanisms are correlated with the generation of cross-resistance by CDDP, including detoxification of cells and increased DNA repair $(37,38)$. Evidence indicates that intracellular GSH content is a determinant of the sensitivity of tumor cells to chemotherapeutic agents (39). BSO inhibits GSH biosynthesis by irreversible inhibition of $\gamma$-glutamyl cysteine synthase and NAC is a thiol antioxidant and cysteine source for GSH synthesis. In the present study, SGC7901/DDP cells were shown to have higher basal GSH levels than the parent cells and this positively correlated with increased cross-resistance to 5-FU and MMC. Modification of the GSH levels in the SGC7901/DDP cells by treatment with NAC or BSO resulted in changes in the sensitivities of the cells to the drugs. Following the inhibition of GSH synthesis by BSO, SGC7901/DDP cells lost their resistance to 5-FU and MMC, whereas NAC supplementation increased the resistance of the SGC7901/DDP cells to 5-FU and MMC treatment. Similar results have been described previously in other cell lines overexpressing MRP1 $(40,41)$. It therefore appears that the cross-resistance of tumor cells depends on their levels of GSH. According to previous studies, GSH is important for promoting the refractory response of tumor cells to cytotoxic drugs via increased expression of P-gp and MRPs (42-44). Intracellular GSH levels are closely correlated with MRP-mediated multidrug resistance since GSH interacts directly with MRP and this interaction causes a change in MRP structure that facilitates the binding and transport of anticancer drugs (45). Alternatively, GSH and anticancer drugs may spontaneously form a complex that behaves as an MRP substrate. Unlike the SGC7901/DDP cells, the SGC7901 cells treated with BSO did not undergo a reduction in $\mathrm{IC}_{50}$ value for $\mathrm{MMC}$, although they were sensitized to 5-FU. Interestingly, the sensitivities of the SGC7901 cells to MMC were upregulated following NAC pretreatment, but the resistance of the cells to 5-FU was not significantly altered by the same treatment. It is therefore possible that the changes of intracellular GSH levels have a greater effect on the chemosensitivity of the resistant cells than on that of the parent cells.

To verify this hypothesis, we evaluated the changes of the GSH levels in the cells following various treatments. The results reveal that NAC increased the GSH levels in the two cell lines but did not significantly reverse the inhibitory effect of BSO. Due to the irreversible effects of BSO, the addition of NAC did not increase the GSH levels immediately, although it had a significant $(\mathrm{p}<0.05)$ effect in the cells compared with treatment with BSO alone. The GSH levels were reduced from their control levels by the BSO treatment more markedly in the resistant cells than in the parent cells. NAC increased the GSH levels whereas BSO markedly reduced GSH synthesis in the two cell lines. When compared with the SGC7901 cells, the $\mathrm{IC}_{50}$ values of the resistant cells were more markedly affected by the variation of GSH levels. We propose that, upon addition of BSO, GSH depletion contributes to the substantial increase in the drug cytotoxicity in the resistant cells. However, NAC appears to have the opposite effect. The results of our study confirm the 
hypothesis that intracellular GSH levels have a close correlation with MDR. With reference to previous studies, we speculate that the mechanism involves the following: i) The depletion of GSH with BSO treatment, resulting in the downregulation of MRP1 expression, correlates with apoptosis in various cell lines. Therefore, GSH plays an important role in the inhibition of apoptosis $(43,46,47)$; ii) GSH is important for the metabolic detoxification of drugs together with increased activities of glutathione S-transferases, which may also protect cells from cytotoxic drugs, so the SGC7901/DDP cells exhibited more resistance than the control (48); iii) the redox-regulating capacity of GSH leads to detoxification in cells expressing high levels of MRP1 (49). Consistent with our results, certain previous studies using human MCF7 cells and A549 cells have shown that changes in intracellular GSH levels give rise to clear alterations in multidrug resistance $(50,51)$. As shown in earlier studies of BSO and in the current study, BSO is capable of suppressing intracellular GSH levels and increasing chemosensitivity. The sensitization of resistant cells may be a promising strategy for overcoming drug resistance in cancer patients, particularly those in whom drug resistance occurs as a result of high GSH levels.

Our results demonstrate that NAC increases multidrug resistance in SGC7901/DDP cells and that this effect may relate to GSH synthesis. Additionally, BSO appears to play a vital role in enhancing the sensitivity to chemotherapeutic drugs via GSH depletion. In summary, our study suggests that the alteration of the intracellular micro-environment redox state changes the multidrug resistance in vitro. This primary research may provide a promising strategy for anticancer therapy.

\section{Acknowledgements}

The authors thank the Teaching and Research Section of Nuclear Medicine, Anhui Medical University for its support.

\section{References}

1. Pisani P, Parkin DM, Bray F and Ferlay J: Estimates of the worldwide mortality from 25 cancers in 1990 . Int J Cancer 83 : 870-873, 1999.

2. Alberts SR, Cervantes A and van de Velde CJ: Gastric cancer: epidemiology, pathology and treatment. Ann Oncol 14 (Suppl 2): ii31-ii36, 2003.

3. Shibuya K, Mathers CD, Boschi-Pinto C, Lopez AD and Murray CJ: Global and regional estimates of cancer mortality and incidence by site: II. Results from the global burden of disease 2000. BMC Cancer 2: 37, 2002.

4. Meads MB, Hazlehurst LA and Dalton WS: The bone marrow microenvironment as a tumor sanctuary and contributor to drug resistance. Clin Cancer Res 14: 2519-2526, 2008.

5. Parmar K, Mauch P, Vergilio JA, Sackstein R and Down JD: Distribution of hematopoietic stem cells in the bone marrow according to regional hypoxia. Proc Natl Acad Sci USA 104 5431-5436, 2007.

6. Glimelius B, Ekström K, Hoffman K, et al: Randomized comparison between chemotherapy plus best supportive care with best supportive care in advanced gastric cancer. Ann Oncol 8: 163-168, 1997.

7. Hill ME and Cunningham D: Medical management of advanced gastric cancer. Cancer Treat Rev 24: 113-118, 1998.

8. Macdonald JS, Smalley SR, Benedetti J, et al: Chemoradiotherapy after surgery compared with surgery alone for adenocarcinoma of the stomach or gastroesophageal junction. N Engl J Med 345: 725-730, 2001

9. Cunningham D, Allum WH, Stenning SP, et al: Perioperative chemotherapy versus surgery alone for resectable gastroesophageal cancer. N Engl J Med 355: 11-20, 2006.
10. Petty RD, Nicolson MC, Kerr KM, Collie-Duguid E and Murray GI: Gene expression profiling in non-small cell lung cancer: from molecular mechanisms to clinical application. Clin Cancer Res 10: 3237-3248, 2004

11. Stavrovskaya AA: Cellular mechanisms of multidrug resistance of tumor cells. Biochemistry (Moscow) 65: 95-106, 2000.

12. Banerjee D, Mayer-Kuckuk P, Capiaux G, Budak-Alpdogan T, Gorlick R and Bertino JR: Novel aspects of resistance to drugs targeted to dihydrofolate reductase and thymidylate synthase. Biochim Biophys Acta 1587: 164-173, 2002.

13. Larsen AK, Escargueil AE and Skladanowski A: Resistance mechanisms associated with altered intracellular distribution of anticancer agents. Pharmacol Ther 85: 217-229, 2000.

14. Ross DD: Novel mechanisms of drug resistance in leukemia. Leukemia 14: 467-473, 2000.

15. Litman T, Druley TE, Stein WD and Bates SE: From MDR to MXR: New understanding of multidrug resistance systems, their properties and clinical significance. Cell Mol Life Sci 58: 931-959, 2001.

16. Narasaki F, Oka M, Nakano R, Ikeda K, Fukuda M, Nakamura T, Soda H, Nakagawa M, Kuwano M and Kohno S: Human canalicular multispecific organic anion transporter (cMOAT) is expressed in human lung, gastric, and colorectal cancer cells. Biochem Biophys Res Commun 240: 606-611, 1997.

17. Nakamura T, Oka M, Aizawa K, Soda H, Fukuda M, Terashi K, Ikeda K, Mizuta Y, Noguchi Y, Kimura Y, et al: Direct interaction between a quinoline derivative, MS-209, and multidrug resistance protein (MRP) in human gastric cancer cells. Biochem Biophys Res Commun 255: 618-624, 1999.

18. Tomonaga M, Oka M, Narasaki F, Fukuda M, Nakano R, Takatani H, Ikeda K, Terashi K, Matsuo I, Soda H, et al: The multidrug resistance-associated protein gene confers drug resistance in human gastric and colon cancers. Jpn J Cancer Res 87: 1263-1270, 1996

19. Hao Z, Li X, Qiao T, Du R, Hong L and Fan D: CIAPIN1 confers multidrug resistance by upregulating the expression of MDR-1 and MRP-1 in gastric cancer cells. Cancer Biol Ther 5: 261-266, 2006.

20. Maeda S, Sugiura T, Saikawa Y, Kubota T, Otani Y, Kumai K and Kitajima M: Docetaxel enhances the cytotoxicity of cisplatin to gastric cancer cells by modification of intracellular platinum metabolism. Cancer Sci 95: 679-684, 2004

21. Tang XQ, Bi H, Feng JQ and Cao JG: Effect of curcumin on multidrug resistance in resistant human gastric carcinoma cell line SGC7901/VCR. Acta Pharmacol Sin 26: 1009-1016, 2005.

22. Chen Y, Ji L, Wang H and Wang Z: Intracellular glutathione plays important roles in pyrrolizidine alkaloids-induced growth inhibition on hepatocytes. Environ Toxicol Pharmacol 28: 357-362, 2009.

23. Kosower NS and Kosower EM: The glutathione status of cells. Int Rev Cytol 54: 109-160, 1978.

24. Markman M: Antineoplastic agents in the management of ovarian cancer: current status and emerging therapeutic strategies. Trends Pharmacol Sci 10: 515-519, 2008

25. Muggia F: Platinum compounds 30 years after the introduction of cisplatin: implications for the treatment of ovarian cancer. Gynecol Oncol 112: 275-281, 2009.

26. Lustberg MB and Edelman MJ: Optimal duration of chemotherapy in advanced non-small cell lung cancer. Curr Treat Options Oncol 8: 38-46, 2007.

27. Matthews GM, Howarth GS and Butler RN: Nutrient and antioxidant modulation of apoptosis in gastric and colon cancer cells. Cancer Biol Ther 5: 569-572, 2006.

28. Podder S, Chattopadhyay A, Bhattacharya S, Ray MR and Chakraborty A: Fluoride-induced genotoxicity in mouse bone marrow cells: effect of buthionine sulfoximine and N-acetyl-Lcysteine. J Appl Toxicol 31: 618-625, 2011.

29. Beketić-Oresković L, Osmak M and Jaksić M: Human larynx carcinoma cells resistant to cis-diamminedichloroplatinum(II): mechanisms involved in the resistance. Neoplasma 41: 163-169, 1994.

30. Balendiran GK, Dabur R and Fraser D: The role of glutathione in cancer. Cell Biochem Funct 22: 343-352, 2004.

31. Akiyama SI, Chen ZS, Sumizawa T and Furukawa T: Resistance to cisplatin. Anticancer Drug Des 14: 143-151, 1999.

32. Panasci L, Paiement JP, Christodoulopoulos G, Belenkov A, Malapetsa A and Aloyz R: Chlorambucil drug resistance in chronic lymphocytic leukemia: the emerging role of DNA repair. Clin Cancer Res 7: 454-461, 2001.

33. Bredel M: Anticancer drug resistance in primary human brain tumors. Brain Res Rev 35: 161-204, 2001. 
34. Germann UA: P-glycoprotein - a modulator of multidrug resistance in tumor cells (Review). Eur J Cancer 32A: 927-944, 1996.

35. Müller M, Meijer C, Zaman GJ, et al: Overexpression of the gene encoding the multidrug resistance-associated protein results in increased ATP-dependent glutathione S-conjugate transport. Proc Natl Acad Sci USA 91: 13033-13037, 1994.

36. Hipfner DR, Deeley RG and Cole SP: Structural, mechanistic and clinical aspects of MRP1. Biochim Biophys Acta 1461: 359-376, 1999

37. Siddik ZH: Cisplatin: mode of cytotoxic action and molecular basis of resistance. Oncogene 22: 7265-7279, 2003.

38. Wang D and Lippard SJ: Cellular processing of platinum anticancer drugs. Nat Rev Drug Discov 4: 307-320, 2005.

39. Kang YH, Lee E, Youk HJ, Kim SH, Lee HJ, Park YG and Lim SJ: Potentiation by alpha-tocopheryl succinate of the etoposide response in multidrug resistance protein 1-expressing glioblastoma cells. Cancer Lett 217: 181-190, 2005.

40. Jin J, Huang M, Wei HL and Liu GT: Mechanism of 5-fluorouracil required resistance in human hepatocellular carcinoma cell line Bel(7402). World J Gastroenterol 8: 1029-1034, 2002.

41. Xu BH and Singh SV: Effect of buthionine sulfoximine and ethacrynic acid on cytotoxic activity of mitomycin $\mathrm{C}$ analogues BMY 25282 and BMY 25067. Cancer Res. 52: 6666-6670, 1992.

42. Chen HH and Kuo MT: Role of glutathione in the regulation of Cisplatin resistance in cancer chemotherapy. Met Based Drugs 2010 pii: 430939, 2010.

43. Akan I, Akan S, Akca H, Savas B and Ozben T: Multidrug resistance-associated protein 1 (MRP1) mediated vincristine resistance: effects of $\mathrm{N}$-acetylcysteine and Buthionine sulfoximine. Cancer Cell Int 5: 22, 2005.
44. Jin WS, Kong ZL, Shen ZF, Jin YZ, Zhang WK and Chen GF: Regulation of hypoxia inducible factor-1 $\alpha$ expression by the alteration of redox status in HepG2 cells. J Exp Clin Cancer Res 30: 61, 2011.

45. Franco R and Cidlowski JA: Apoptosis and glutathione: beyond an antioxidant. Cell Death Differ 16: 1303-1314, 2009.

46. Akan I, Akan S, Akca H, Savas B and Ozben T: N-acetylcysteine enhances multidrug resistance-associated protein 1 mediated doxorubicin resistance. Eur J Clin Invest 34: 683-689, 2004.

47. Chuman Y, Chen ZS, Seto K, et al: Reversal of MRP-mediated vincristine resistance in $\mathrm{KB}$ cells by buthionine sulfoximine in combination with PAK-104P. Cancer Lett 129: 69-76, 1998.

48. Schafer FQ and Buettner GR: Redox environment of the cell as viewed through the redox state of the glutathione disulfide/ glutathione couple. Free Radical Biol Med 30: 1191-1212, 2001.

49. Commandeur JN, Stijntjes GJ and Vermeulen NP: Enzymes and transport systems involved in the formation and disposition of glutathione S-conjugates. Role in bioactivation and detoxification mechanisms in xenobiotics. Pharmacol Rev 47: 271-330, 1995.

50. Benderra Z, Trussardi A, Morjani H, Villa AM, Doglia SM and Manfait M: Regulation of cellular glutathione modulates nuclear accumulation of daunorubicin in human MCF7 cells overexpressing multidrug resistance associated protein. Eur J Cancer 36: 428-434, 2000.

51. Han YH, Moon HJ, You BR, Kim SZ, Kim SH and Park WH: The effects of N-acetyl cysteine on the MG132 proteasome inhibitor-treated lung cancer cells in relation to cell growth, reactive oxygen species and glutathione. Int J Mol Med 25: 657-62, 2010. 